\title{
PHM Based Adaptive Power Management System for a More Electric Aircraft
}

\author{
Robin.K.Sebastian ${ }^{1}$, Suresh Peripinayagam ${ }^{2}$, and Alireza Alghassi ${ }^{3}$ \\ ${ }^{1}$ Hindustan Aeronautics Limited, Aircraft Research and Design Center, Bangalore, Karnataka, 560037, India. \\ robin.kuttikkadan-sebastian@cranfield.ac.uk,robinksebastian@yahoo.co.in \\ ${ }^{2,3}$ IVHM Centre, Cranfield University, Bedfordshire, Bedford, MK43 OAP, UK. \\ suresh.nayagam@cranfield.ac.uk,a.alghassi@cranfield.ac.uk
}

\begin{abstract}
This research work presents a novel approach that addresses the concept of an adaptive power management system design and development framed in the Prognostics and Health Monitoring(PHM) perspective of an Electrical power Generation and distribution system(EPGS).PHM algorithms were developed to detect the health status of EPGS components which can accurately predict the failures and also able to calculate the Remaining Useful Life(RUL), and in many cases reconfigure for the identified system and subsystem faults. By introducing these approach on Electrical power Management system controller, we are gaining a few minutes lead time to failures with an accurate prediction horizon on critical systems and subsystems components that may introduce catastrophic secondary damages including loss of aircraft. The warning time on critical components and related system reconfiguration must permits safe return to landing as the minimum criteria and would enhance safety. A distributed architecture has been developed for the dynamic power management for electrical distribution system by which all the electrically supplied loads can be effectively controlled. The different failure modes were generated by injecting faults into the electrical power system using a fault injection mechanism. The data captured during these studies have been recorded to form a "Failure Database" for electrical system. A hardware in loop experimental study was carried out to validate the power management algorithm with FPGA-DSP controller. In order to meet the reliability requirements a Tri-redundant electrical power management system based on DSP and FPGA has been developed.
\end{abstract}

Robin.K.Sebastian et al. This is an open-access article distributed under the terms of the Creative Commons Attribution 3.0 United States License, which permits unrestricted use, distribution, and reproduction in any medium, provided the original author and source are credited.

\section{INTRODUCTION}

The Electrical power Generation and distribution system (EPGS) is a key airframe system on any of modern aircraft. During the recent past there has been a drastic improvement in the study of power electronics, power conversion, High density energy storage and fault tolerant electrical machines. More Electric and All Electric Aircraft are the emerging trends in aerospace vehicle design (Rosero, Ortega, Aldabas and Romeral ,2007).Electric propulsion is considered as the future mode of aircraft propulsion.Turbo-electric Distributed propulsion(Te-DP) utilizes the advanced electric power converters, Electric fans and power management systems for the cleaner, lean, quiet and efficient electric propulsion were studied(Felder, Kim and DandBrown,G.V,2009).The Electro Mechanical Actuator(EMA),Electrical ECS and Ice protection with elimination of engine bleed are the emerging trends in the aerospace industry. The Electrical power management system based load scheduling is the new trend in aircraft electrical power system design. This approach will optimize the use of electrical power sources in an aircraft and make the system more fault tolerant (AbdElhafez and Forsyth, 2009). Conventional Electrical Load management system works based on the fixed priority algorithm for load scheduling which is not an efficient approach. A microeconomic model based cost functions are formed to combine variable priority and efficiency of the electrical load to a single control variable. Based on the cost function optimization algorithm, a power control membership function is generated. In the conventional IDG modelling both PMG and Exciter Generator modelled as a constant voltage source which is not an effective method for studying the structural faults in EPGS System. A hybrid modelling method for the IDG system is proposed. Various IDG faults such as parametric and structural faults are studied. Experimental testing and verification of the generator has been done at IDG Rig, Cranfield University. The PHM based RUL data and health index information were fused into 
electrical power management algorithm to make it fault tolerant.

There has been research works happening on PHM of EPGS system and Power Management Based More Electric Aircraft Design. However, there is very less research works happening for combining both MEA and PHM concept in a single platform. This research work aims at design and development of a PHM based Electrical Power Management which is based on PHM, variable priority Load scheduling and optimization of power capacity. These approach will reduce the Direct Operating Cost (DOC) which is largely depends on amount of fuel burned and maintenance cost in the civil aircraft. The power and efficiency optimization has the advantage that aircraft weight penalty due to electrical generator over design for meeting the additional electrical loads can be avoided. Power management methods have an increased impact on overall aircraft efficiency. On the one hand, they can find an optimal operation point of competing power sources. On the other hand, they control electrical or thermal loads to reduce power peaks. This enables downsizing of energy generation and distribution components. Since reducing weight is a key enabler for more electric aircraft, the power/energy management method needs to be incorporated into architecture specification and system design as early as possible. Further improvements can be made by exploiting the dynamic behaviour of slow responding loads. They can be handled like an electrical storage to reduce power peaks while keeping full availability and functionality. This research work is a novel approach in the design of fault tolerant power management design which combines PHM and MEA concept in a single platform.

\subsection{Electrical Power Generation System}

EPGS system consist of Integrated Drive Generator (IDGs) and Transformer Rectifier Unit (TRUs) which will supply electrical power for various critical systems on-board. IDGs are directly mounted on engine gear box which makes the maintenance activity for generator difficult and demands engine and gearbox removal which will add maintenance cost and flight delays. The conventional servicing methods for generator will initiate maintenance activity even with plenty of RUL left for safe operation. An efficient fault diagnosis and prognostic method is required for safe and reliable operation of EPGS system.IDG consist of Permanent Magnet Generator (PMG), Exciter Generator and Main Generator which are mounted on the common rotating shaft. IDG operation is monitored and controlled by Generator Control Unit (GCU). Because of the complex nature of the IDG design, most of the fault detection and isolation techniques are based on the signal analysis and experience of the maintenance technician. Majority of the fault detection and isolation techniques of IDGs are model-free (Tantawy and Biswas, 2008).Building sufficiently accurate models for IDG electrical subsystem is a difficult task because of the complex nonlinearities and the difficulties in defining the dynamics of the electromagnetic behaviour (Tantawy and Biswas, 2008). In the conventional IDG modelling both PMG and Exciter Generator modelled as a constant voltage source which is not an effective method for studying the structural faults in EPGS System. An improved modelling with rectifier bridge model is shown "as given in the research work of (Tantawy and Biswas, 2008)".A hybrid modelling method for the IDG system is proposed with mathematical modelling of PMG, Exciter and Main Generator. Various IDG faults such as parametric and structural faults were studied. Experimental testing and verification of the generator has been done at IDG rig, Cranfield University.

The initial Prognostic research work for synchronous generators are mostly based on the mechanical vibration analysis "as given in the research work of (Todd and Swanson,2009)".Mechanical Bearing studies received most of the attention, failure mode studies shows that rotor field circuit degradation is equally critical, and there for demands a PHM on it "as given in the research work of (Todd and Swanson ,2009)". There are several methods for Fault Detection and Isolation(FDI) in rotor field winding have been studied such as use of search coils to measure airgap flux asymmetry "as given in the research work by (Connally, Lodge, Jackson, and Roberts,1985)",circulating current measurements in the main armature coils for rotor short circuit studies "as given in the (Sottile,Trutt,,and Leedy,2001)" ,Rotating rectifier fault detection in generator "as given in the research work of (Zouaghi,T,and Poloujadoff.M,1998)" are some examples.

Though other works have focused primarily on detection algorithms, this paper addresses each of the main requirements of an effective PHM algorithm implementation of electrical power system which can be used for power management system development. A Failure Mode, Effects and Criticality Analysis (FMECA) is the first steps towards the development of PHM algorithm, which will identify and prioritize various failure modes of electrical generator, converter and contactors. The characteristics and parameter(s) of IDG, TRU and GCU can be obtained from the Electrical power supply standard, MIL-STD-704F.It is necessary to pick up the proper parameters in MIL-STD$704 \mathrm{~F}$ to monitor to avoid the catastrophic failures and raise the maintenance efficiency "as given in the research work of (Pan, Dong, Jiang and Zhang, 2012)". Various IDG faults are parametric faults such as Over Voltage, Arc Fault, Open Contact Fault, Under/Over Voltage, Under/Over speed etc., various structural faults such as ground faults and short circuit faults. FMECA on TRU results failure modes such as diode fault, over temperature fault, under/over voltage fault. Contactor FMECA results various failure modes such as Open/Stuck contact, Energization coil failure, etc.

In this paper we presents a classifications of possible faults that are typically encountered during the operations of generators and TRUs. These data will be used to inject 
various faults to get the failure mode behaviour of the same .As discussed in the previous paragraph FMECA results in various Generator faults which can be subdivided into two major categories such as parametric faults and structural faults "as given in the research work of (Tantawy and Biswas, 2008), (Todd and Swanson, 2009)".Parametric faults are characterized by a change in the magnitude of one (or more) system model parameters. These faults do not affect the structure of the system and system model still valid for failure studies. Various disturbances and uncertainties are injected into the system including various odd harmonies to generator output and rectifier dc output terminals. The parameter spectrum is defined by the Electrical Power supply characteristics, MIL-STD-704F.

Structural faults change the system configuration, which cannot be represented by parameter variation. This needs a new modelling method which represents the various structural faults such as internal and external faults "as given in the research work of (Tantawy and Biswas, 2008), (Todd and Swanson, 2009)".External faults are the ones that happens outside the machine terminals, and although they do not change the structure of the machine, the overall system model will change "as given in the research work of (Todd and Swanson,2009)".Sometimes it is possible to represent external faults by a parameter change by introducing auxiliary elements in the original model, but may not always be possible. Phase to ground and phase to phase short circuit faults are the most critical external faults. An example of an internal fault that changes the structure of the system is one phase to ground fault. The short circuit from winding to the ground creates a new loop with additional current components and with loop voltage equal to zero. The situation becomes more complex when there is a dual fault from two phase to the Ground "as given in the research work of (Tantawy and Biswas, 2008), (Todd and Swanson, 2009)".EPGS system has been mathematically modelled and simulation studies has been carried out using MATLAB Simulink.

The most challenging part of aircraft systems health monitoring was the sensor optimization process and its location identification. A COTS based software called MADe(Maintenance Aware Design Environment) developed by PHM technologies has been used to identify the sensor location and failure mode simulation for electrical power system. The approach involves the qualitative functional modelling of the system in order to have sensor placement and identifying the failure propagation further development of diagnostic rules.

\subsection{Electrical Power Generation System Architecture}

EPGS system for the research work is based on the legacy aircraft platform Boeing 777 which uses hybrid (both AC and DC) electrical generation system, which is further subdivided into Main and Standby system. The main electrical power generation consist of two engine driven IDGs, an APU driven $3^{\text {rd }}$ Generator. The standby EPGS system is consist of two engine driven generators and one integrated converter/control unit.B777 is the first aircraft platform which adopted Electrical load management system. The automation of the system is performed by the state-of-the-art, control units which performs system control, protections and built-in-test functions. The control unit are interfaced to the avionics system through dual redundant Avionics data bus. The single line diagram of EPGS System is as shown in the Figure-1.

(a)The main generator is IDG mounted on each engine,

3-phase, 4 wire, 115V/200V, 400-Hz, 120KVA.

(b)One APU Generator,3

Phase, $115 \mathrm{~V} / 200 \mathrm{~V}, 400 \mathrm{~Hz}, 120 \mathrm{KVA}$

The IDG connected on each engine can supply electrical power to respective main buses through a Generator circuit Breaker. The two main buses are connected by

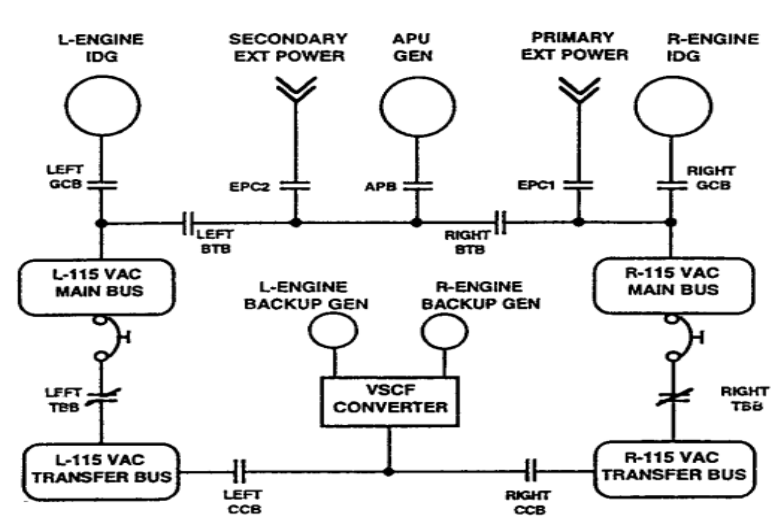

Figure 1. EPGS Architecture

Bus Tie-Breaker (BTB).For loss of electrical power from One IDG, BTB automatically closes, powering both main bus in LH\&RH from a single IDG. Automatic load scheduling is provided to prevent overloading of generator under Singlegenerator operation. The generator mounted on APU is connected in between the BTBs through the Auxiliary Power Breaker (APB) "as given in the research work of (L.Andrade, C.Tenning, 1992)".

The Electrical Load Management Architecture contains two Bus Power Control Units (BPCU) which works as a Data buscontroller as shown in Figure-2. Two Primary Power Distribution Unit (PPDU) are used for controlling the high power loads. The ELMCs are employed for switching and controlling the remaining electrical loads on-board. The MEA contains 3 primary switching panel with Generator Line Contactor (GLC), BTB, External Power Contactor (EPC) and ELCUs. It also contains 4 secondary power control panel with Electronic Unit (EUs) "as given in the research work of (L.Andrade, C.Tenning, 1992), (Xia and Lawson,2013)". 


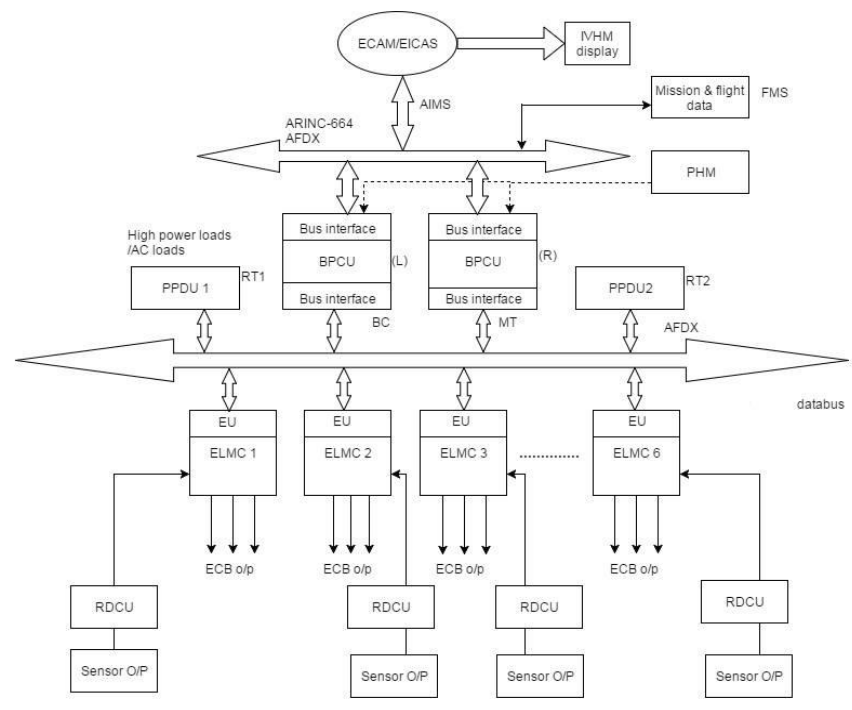

Figure 2. Electrical Power Management Architecture

\section{PHM FRAMe WORK FOR POWER MaNagement SYSTEM}

The health monitoring and data/feature extraction from the existing sensor network including voltage, current, frequency, temperature and vibration were used for the incipient fault detection that can effectively contribute to the fault accommodation using adaptive reconfiguration algorithm which will avoid further damage and eventual failures leading to significant downtime. Different methods for defining the diagnostics and prognostics algorithms were developed "as given in the research work of (Ginart, Barlas, Dorrity, Kalgen and Roemer,2006)".The various data/feature extraction techniques along with the system design knowledge were employed for effective PHM development. Advanced signal processing techniques are used for incipient fault detection, while extracted features and models are used for failure progression tracking. Selected features and model estimates that track well with the health of particular components is fused to determine the Remaining Useful Life Time (RULT) health indices "as given in the research work of (Ginart, Barlas, Dorrity, Kalgen and Roemer, 2006)".Based on this foundation of health state information, complementary prognostics techniques, such as analysis by physics-based component damage accumulation/aging models, is used to determine remaining useful life. Based on the health predictions, adaptive re-configuration methods are used to automatically provide graceful degradation by which comeback and land is the minimum safety criterion for the aircraft.

The presented framework integrates feature and model-based diagnostics and prognostics techniques with a hierarchical automated adaptive algorithm which contains automated fault accommodation for electrical power system as given in Figure-3.
The adaptive algorithm is divided into three distinct levels: Physical (sensor/component- level), regulation (control)level, and EPGS performance-level, as shown in the Figure3. Once the reliable sensor data is available, the process of incipient fault detection and prediction is performed in the PHM block.

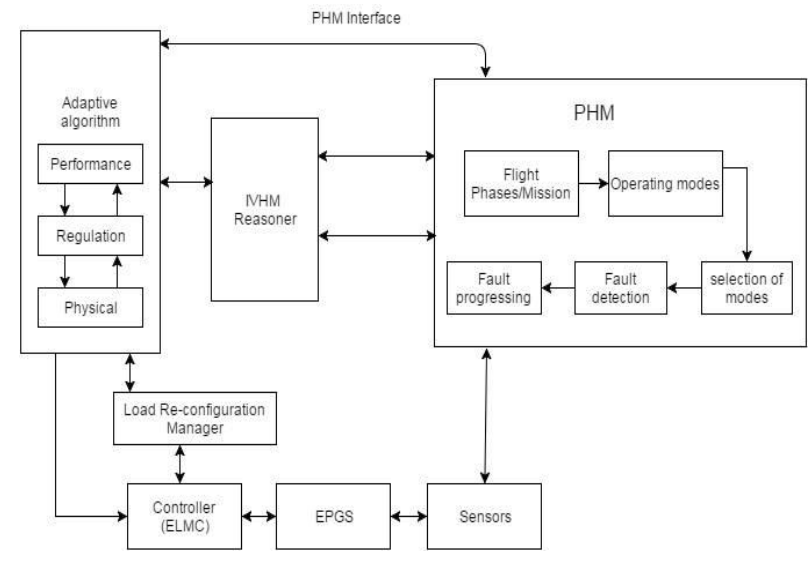

Figure 3. PHM Framework for EPGS System

Once the health state of the electrical system components is determined, predictions on the criticality of the faults with respect to the mission requirements are processed with the "IVHM Reasoner" block shown. The PHM approach for EPGS system will be discussed in the next sections. If the determination is made that an action or intervention is required to ensure safe and reliable operation, then the fault accommodation and adaptive management block is activated. This module first examines the current severity of the fault with respect to the physical components themselves to determine how the system is affected at the control level "as given in the research work of (Ginart, Barlas, Dorrity, Kalgen and Roemer, 2006)".If a failure would produce an catastrophic failure includes loss of aircraft, all available options are examined within the control system to redirect the control authority to healthy systems or reduced load as needed. This is performed with the "Load Re-configuration Manager" block as shown in Figure-3.Finally, the decisions made within the "Load Re-configuration" block are executed by the ELMCs to provide optimal performance based on the degraded condition of the system.

\subsection{Prognostic Health Reasoner for Electrical Generator}

This section explains the prognostic Reasoner development for electrical generator with RUL prediction. A typical PHM process is shown in the Figure-4.In this section we focus on the electrical system modelling of the IDG for the Electrical Power system design. Figure-5 shows the block diagram of the simplified IDG, which also includes the Generator Control Unit (GCU), which employs a feedback loop in the design. The main generator is connected to the electrical system by using Generator Line Contactors (GLCs).GCU 
will compares the measured terminal voltage to a reference value, and regulate the field voltage for the exciter generator.

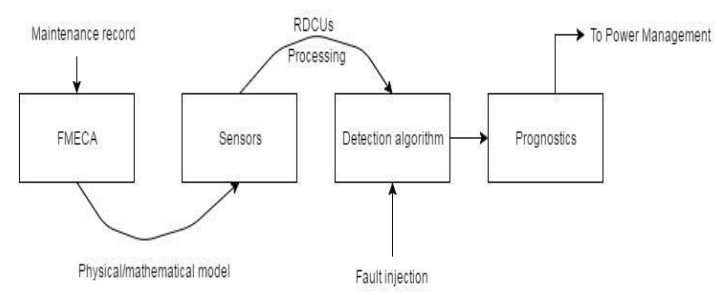

Figure 4. PHM Process in EPGS System

Permanent Magnet Generator (PMG) is used for supplying electrical power for the operation of GCU. The armature of the Exciter, Rectifier and the Main Generator field rotate with the main shaft that drive the entire IDG. The Exciter field, Main generator armature are stationary and the scheme is widely known as brushless Generator. A glossary of variable is listed in the end, where subscript $x \in\left\{a, b, c, K_{q}, f_{d}, K_{d}\right\}$ represents the different generator windings:a,b,c are the 3phase windings, $\mathrm{K}_{\mathrm{q}}$ and $\mathrm{K}_{\mathrm{d}}$ are the two damper windings, and $\mathrm{f}_{\mathrm{d}}$ is the field winding.

As discussed in the introduction, for the detailed analysis of structural faults, a hybrid modelling based IDG design is used. A simplified block diagram of IDG is shown in the Figure 5. The rotating portion of the IDG is highlighted in the gray shaded block. The IDG consist of Permanent Magnet Generator (PMG), Exciter Generator and Main Generator. The IDG operations are monitored and controlled by Generator Control Unit (GCU). For the simulation purpose a PID controller is used as GCU, with a feedback loop gain. Generator Line Contactor (GLC), using power contactor is used to connect generator to the electrical loads. GCU functions monitoring of PMG and Generator Voltages, compare it with the reference values and initiate necessary required action. The GLC are initiated to close by GCU, if all the electrical parameters are within normal limits as specified by MIL-STD-704D.

The permanent Magnet Generator (PMG) is used for providing electrical power for the operation of GCU. The armature of the Exciter, Rectifier and the Main Generator field rotate with the main shaft that drives the entire IDG. The Exciter field, Main generator armature is stationary and the scheme is widely known as brushless Generator. The generated model represented in this paper is useful for general use and different simulation experiments. This model can be dragged and dropped into the EPGS simulation block of the MATLAB Simulink platform and simulation studies have been conducted.

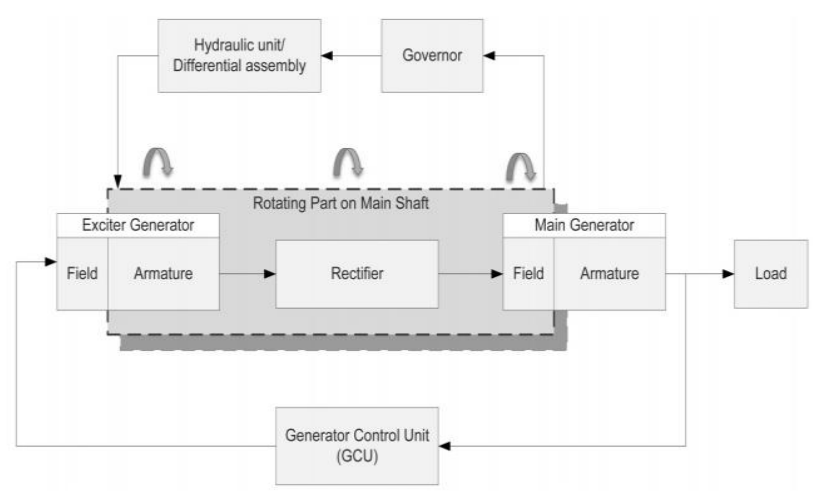

Figure 5. Mathematical Modelling of IDG

CSD generators are designed to provide MIL-STD-704 electrical power quality and performance. One performance requirement relates to voltage and frequency recovery, when high loads are dumped on and off the generator. The CSD typically uses an isochronous speed control (with no speeddroop with load), but it relies upon a closed loop hydraulic servo and electromagnetic governor head trimming. When a sudden load is applied to the generator there is a momentary droop in speed until the servo-loop corrects for the deviation by an adjustment to the hydraulic/spool-valve. Thus the performance characteristic of the drive depends upon the loop gain, loop dynamics, and the inertia constants of the drive.

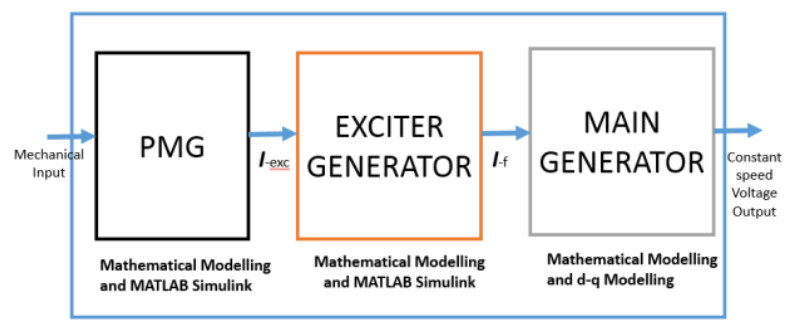

Figure 6. Mathematical Modelling of IDG

In the conventional IDG modelling both PMG and Exciter are assumed to be constant voltage source which is not a suitable method for structural fault analysis.

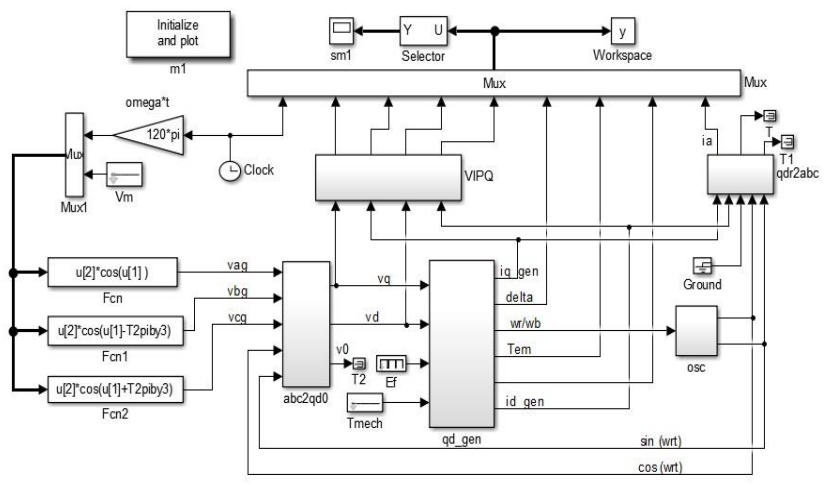

Figure-7. d-q Modelling of IDG 
A hybrid modelling of IDG is proposed as given in Figure6.PMG is modelled using MATLAB Simulink and the performance plot is given in the Figure- 8 . The output of the PMG is fed to the exciter generator field $\left(\mathrm{i}_{\mathrm{exc}}\right)$ and will excite the exciter field winding. GCU will monitor the performance of PMG and will control the exciter current. A better mathematical modelling with rectifier bridge modelling was used (Tantawy and Biswas, 2008). For the modelling of exciter generator same methodology was followed. Details of IDG mathematical modelling is given in Appendix.

A d-q transformation based Main Generator model is shown in Figure-7. PMG is modelled using MATLAB Simulink and performance plot is shown in Figure-8.

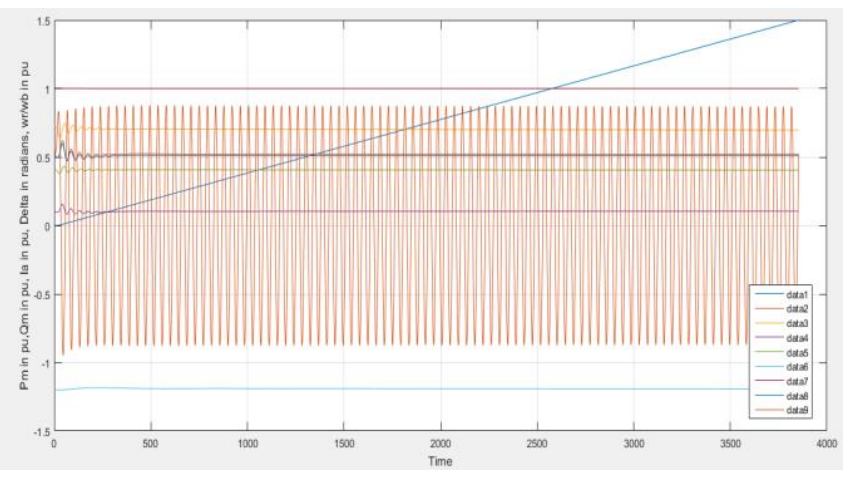

Figure 8. Plot of PMG Performance

The short circuit fault test has been carried out on main generator and the variation in armature current and related torque variations are shown in Figure-9. The single phase half wave bridge rectifier is used for the failure mode analysis of exciter generator. The diode resistance were varied and voltage plots are shown in Figure-12.

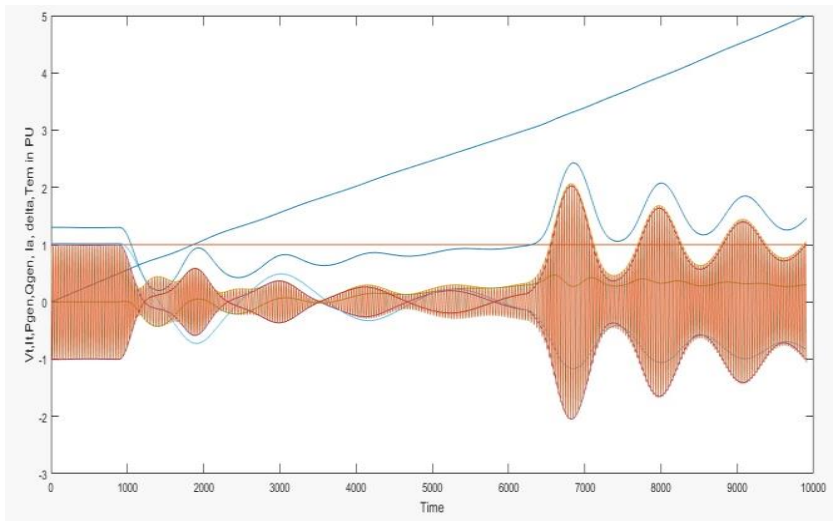

Figure 9. Short Circuit Fault in Main Generator

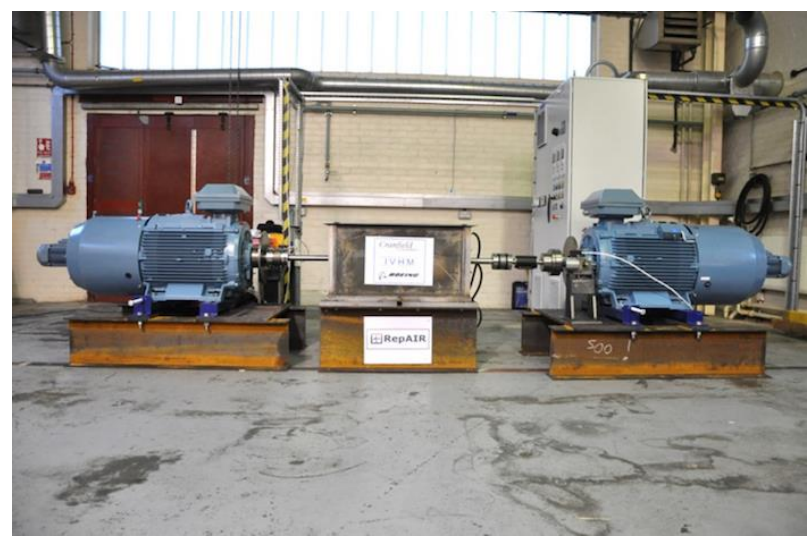

Figure 10. Experimental testing at IDG Rig
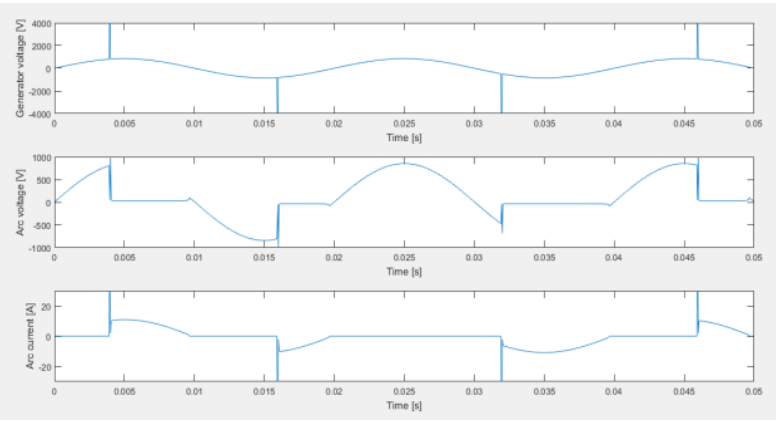

Figure 11. Over Voltage testing at Main Generator

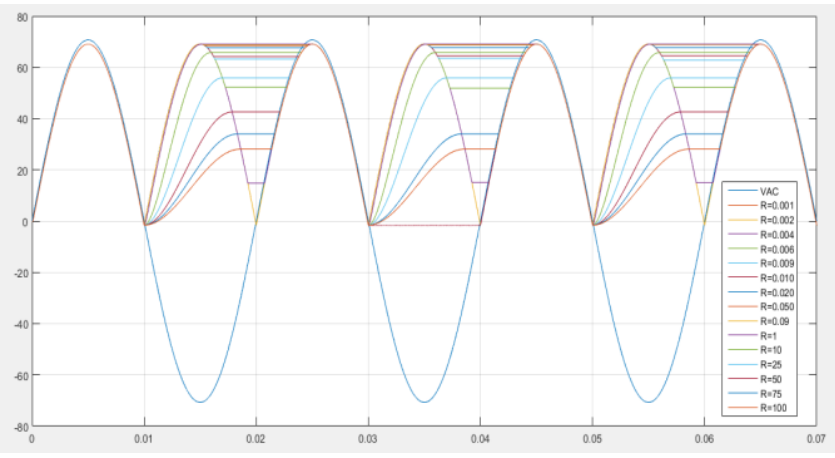

Figure 12. Exciter Generator Bridge Rectifier testing

GCU is modelled as a simple PID controller. The input to GCU (RMS value for the main generator 3-phase voltages) is compared to the reference value, and the error signal is the input to the PID controller.

The generated model represented in this paper is useful for general use and different simulation experiments. This model can be dragged and dropped into EPGS simulation block of 
MATLAB Simulink platform and simulation studies has been conducted.

\subsection{PHM Reasoner Development for TRU}

The Transformer Rectifier Unit converts $115 \mathrm{~V} / 200 \mathrm{~V}, 400 \mathrm{~Hz}$ supply into relatively smooth 28DC system. Rectifier and filter is the key components inside a TRU which provide smooth DC output voltage (28VDC).TRU output can reach 250Amps or higher. TRU is working at high temperature condition which can lead to the failure of electronic components inside. The cooling fan temperature variation can be monitored for TRU heat dissipation by the transformer and rectifier modules. The variation in the ripple content in the DC output terminal can be considered as the feature for PHM analysis. The RUL calculation and health index function generation is similar to IDG. In this paper IDG alone is taken as case study for RUL calculation.

\subsection{PHM Reasoner Development for Contactor/Relays}

Various failure modes for the contactor have been identified using FMECA analysis. A Bayesian based PHM approach has been selected for the PHM analysis. The contactor resistance variation is selected as the signature feature for fault tracking and RUL calculation as shown in Figure-13.

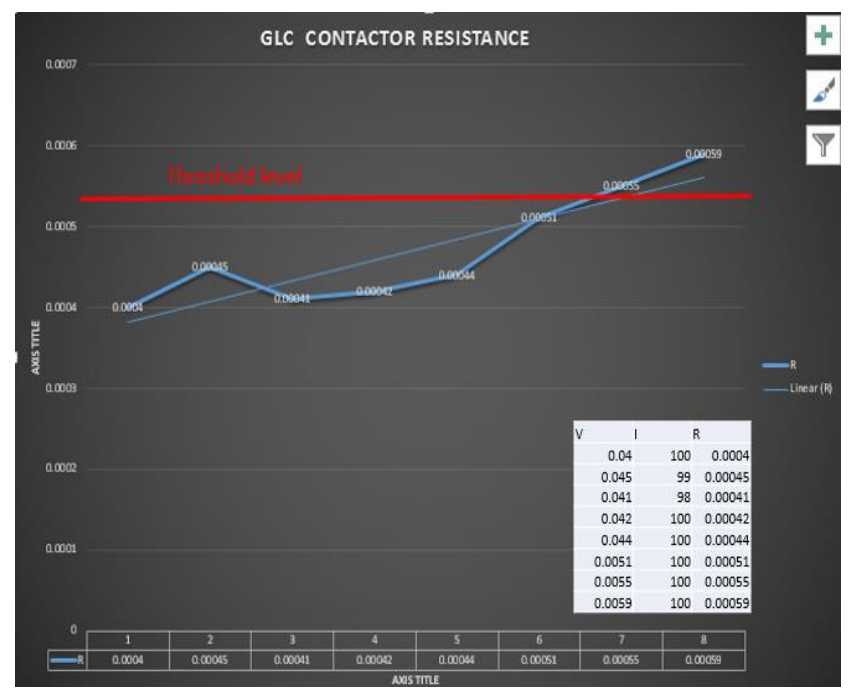

Figure 13. Contactor Resistance Variation

The contactor mathematical modelling has been carried out. The sensor identification and mathematical model is shown in Figure 14.

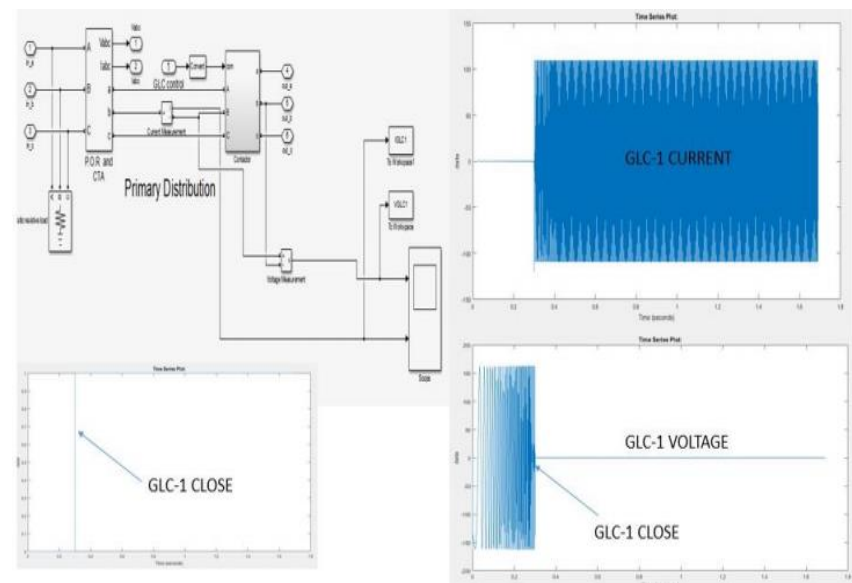

Figure 14. Electrical Contactor Simulink Block

\subsection{Failure injection modules}

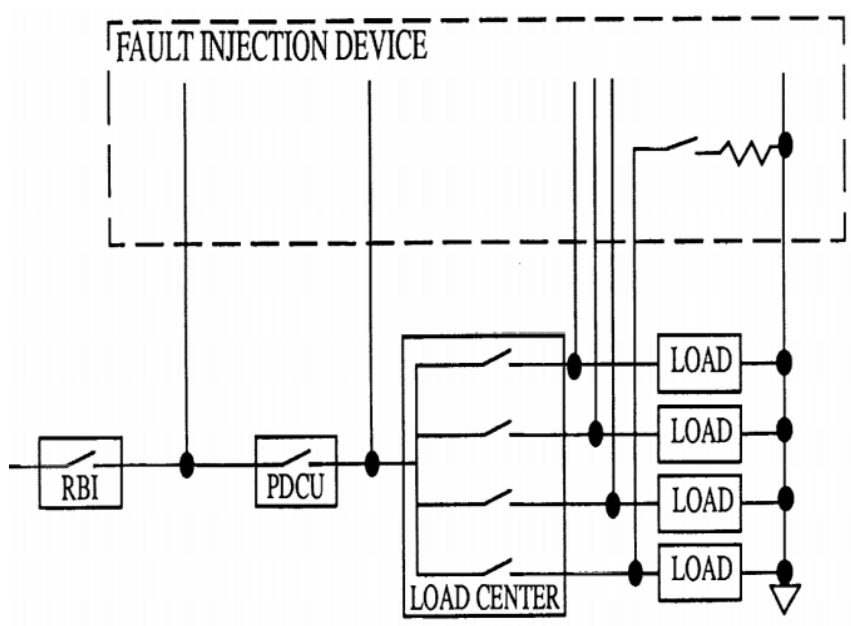

Figure 15. Various Failure injection methods

The Fault injection unit used for the simulation studies is shown in Figure 15. Various External faults including the short circuit faults are simulated.

The mathematical model developed in the previous sections have been inserted in to MATLAB based EPGS system and simulation studies has been carried out. These studies were done to collect data during various failure modes including Parametric and structural Faults. These data were recorded for the generation of Fault database for EPGS System.

The combined Diagnostic and Prognostic Algorithm for EPGS System has been developed and given in Figure-16. 


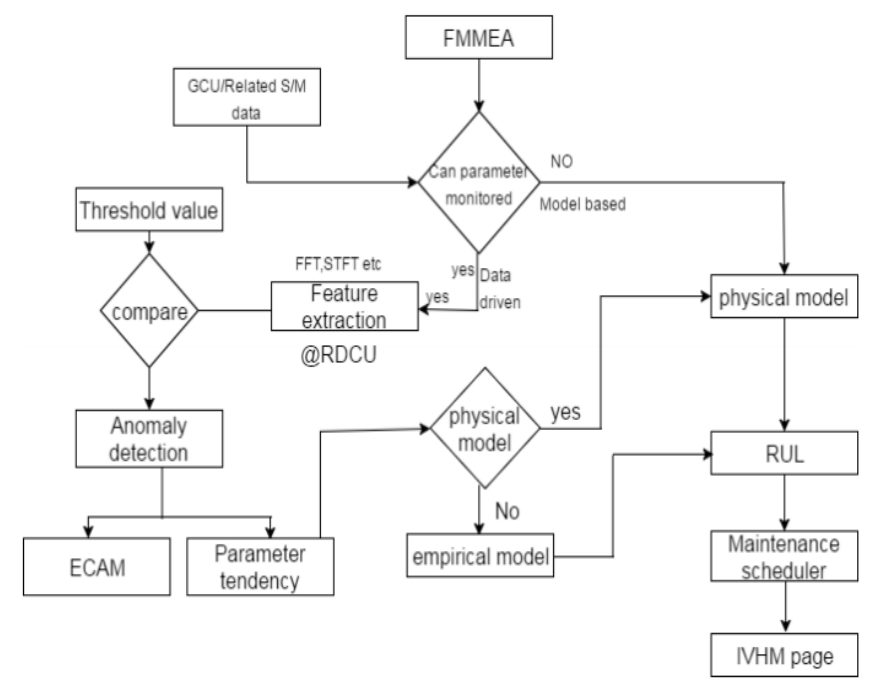

Figure 16. PHM for EPGS System

The Engine Interface and Crew Alert System (EICAS or ECAM) interface has been used for better Human Machine Interface which will be displaying all the important and essential information, messages and warning to the pilot. The Data and Feature extracted for EPGS system is given in Table-1.

\begin{tabular}{|l|l|l|l|l|}
\hline $\begin{array}{l}\text { Aircraft } \\
\text { system }\end{array}$ & Failure modes & $\begin{array}{l}\text { Monitoring } \\
\text { Required }\end{array}$ & Sensor Types & $\begin{array}{l}\text { Analysis } \\
\text { methods }\end{array}$ \\
\hline & $\begin{array}{l}\text { Shorted Rotating } \\
\text { Diode fault } \\
\text { Generator Under } \\
\text { Voltage }\end{array}$ & $\begin{array}{l}\text { Voltage, } \\
\text { Current, } \\
\text { Frequency }\end{array}$ & $\begin{array}{l}\text { Voltage } \\
\text { Sensors } \\
\text { Current } \\
\text { Sensors }\end{array}$ & $\begin{array}{l}\text { Model based } \\
\text { Approach }\end{array}$ \\
\hline $\begin{array}{l}\text { Electrical } \\
\text { System }\end{array}$ & $\begin{array}{l}\text { Generator/Bus Tie } \\
\text { Contactor (BTC) } \\
\text { failure }\end{array}$ & $\begin{array}{l}\text { Contactor } \\
\text { Resistance }\end{array}$ & $\begin{array}{l}\text { Voltage across } \\
\text { The contactor }\end{array}$ & $\begin{array}{l}\text { Data driven } \\
\text { approach }\end{array}$ \\
& $\begin{array}{l}\text { Turn-On time, } \\
\text { No Of Cycles } \\
\text { of Operation }\end{array}$ & $\begin{array}{l}\text { Current } \\
\text { through BTC }\end{array}$ & \\
\hline $\begin{array}{l}\text { Rilter component } \\
\text { failure }\end{array}$ & $\begin{array}{l}\text { Ripple } \\
\text { content, } \\
\text { Rectifier } \\
\text { voltage and } \\
\text { current }\end{array}$ & $\begin{array}{l}\text { Rectifier } \\
\text { Voltage }\end{array}$ & $\begin{array}{l}\text { Rectifier } \\
\text { Current }\end{array}$ & $\begin{array}{l}\text { Model based } \\
\text { Approach }\end{array}$ \\
\hline
\end{tabular}

Table 1. PHM Features for EPGS System

Data driven and model based approach has been used for PHM algorithm development.

The fault injection studies were carried out to identify the signature features is linked to the generator health status. The diagnostics and prognostics of the rotor circuit can be carried out by effective tracking of the trajectory of this features. Kalman filter is used for the trajectory tracking of the captured features. IDG is taken as the case study component for RUL prediction and health index function design. A better RUL prediction algorithm was given in the recent research work (Todd and Swanson, 2009). The kinematic equation for the Kalman filter design for the trajectory tracking of the features for EPGS is given in $\mathrm{Eq}(1)$ and $\mathrm{Eq}(2)$. Where $\mathrm{x}, \mathrm{x} ; \mathrm{x}^{*}$ are the present value, rate of change and acceleration value of the respective features.

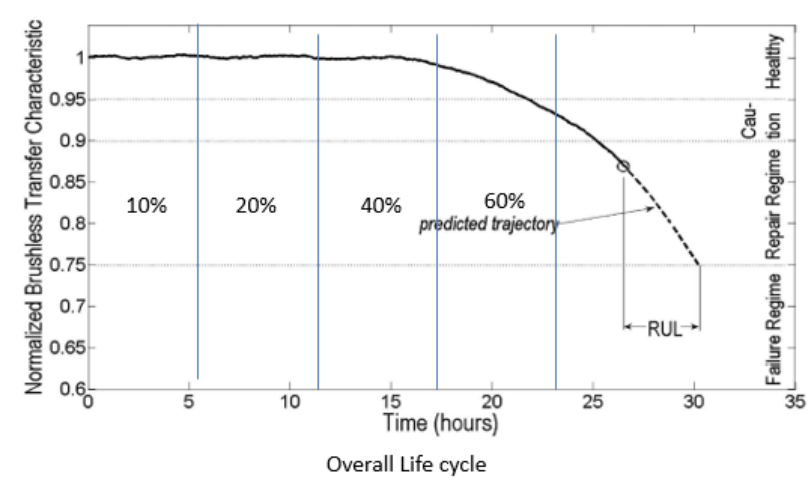

Figure 17. IDG RUL prediction

$$
\begin{aligned}
& x_{k}=x_{k-1}+\dot{x}_{k-1} \tau+\frac{1}{2} \ddot{x}_{k-1} \tau^{2} . \\
& \mathbf{x}_{k}=\left[\begin{array}{lll}
x_{k} & \dot{x}_{k} & \ddot{x}_{k}
\end{array}\right]^{\mathrm{T}} .
\end{aligned}
$$

The IDG RUL tracking data is shown in the Figure-17. It is spread across the lifecycle of IDG. Once a fault is detected inside IDG by the PHM algorithm, the health index and RUL values are calculated and tracking is initiated. Based on the number of hours/cycles it is used along with detection algorithm, health status will vary and divided as 'Low', 'Medium' and 'High'. A health index membership function is generated as shown in Figure-19.

The fault progression behaviour and RUL can be recorded in a database to be called by the power management algorithm. A typical RUL plot for EPGS components is shown in the Figure-18.

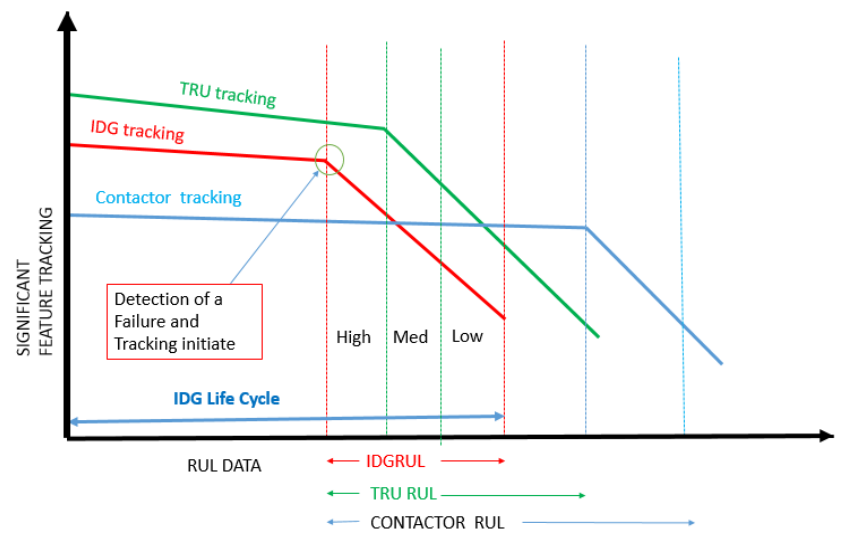

Figure 18. RUL for EPGS Components

Figure-18 shows a case study for IDG RUL prediction. As discussed in the previous sections, the exciter rectifier diode 
is considered as the component which has a failure. The health deterioration is monitored using the tracking of rectifier output voltage as discussed in Figure-12. Based on the performance results the IDG RUL is predicted and divided into various RUL bands as given in Figure-17.

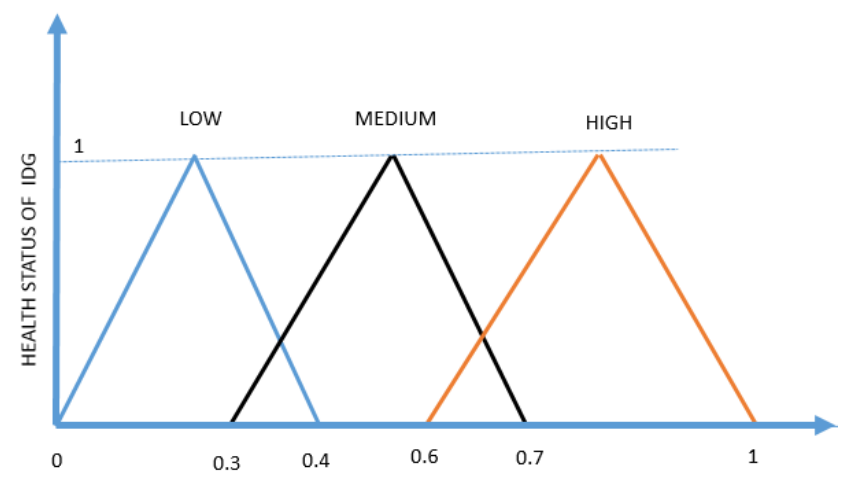

Figure 19. IDG Health Status Membership function

Figure-18 shows a scenario in which IDG fault detected by PHM algorithm. IDG, TRU and Power contactor has different RUL values and health status. The EPGS overall RUL depends on the least RUL component in the architecture and its significance in power distribution. Consider a case in which IDG has a fault detected and RUL value is calculated. Based on the available reconfiguration options considering the safety issues, an optimum solution is identified by Power Management System. There are options such as continue IDG with reduced loads, switch off IDG and consider standby options, etc. The reconfiguration algorithm should consider RUL and health data as the primary PHM indicators. The RUL value is high for a newly installed component. Whenever a component replacement is occurred, PHM data base should be updated for an effective RUL calculation.Health status membership function generated for IDG is shown in Figure-19. Fuzzy logic based algorithm is used for defining the health status membership function.

\section{Electrical Power Management Algorithm DEVELOPMENT}

PHM based Power management system is used for controlling the electrically powered loads on board throughout every flight phases/mission. The electrical loads are controlled using Solid State Power Controllers (SSPC) and Electronic Circuit Breakers (ECB). These SSPCs are activated by using the power management algorithm which uses the Power demand request, Electrical Load analysis, Prediction about the future demand, Variable load priority as per flight phases and mission performance, RUL of the individual components and Health status distribution function. The switching transients study with harmonics generation at generator and rectifier terminals and optimal load switching profile were carried out.
The power management system is used for MEA and AEA to have minimum system weight and effective utilization of the power resources on board. The conventional fixed priority load management algorithm has been replaced by variable priority loading profile with different flight phases and mission requirements. The power management algorithm will do a trade-off study between stability of EPGS system while reconfiguration and generator efficiency during load management. The power management algorithm will make use of the feasibility of exploiting the slow responding electrical loads such as Galleys, ECS and Wing Ice protection system by using it as an energy storage devices. A detailed load analysis w.r.t flight phases is a key element for developing the power management algorithm. The overload operation envelop of generator can be exploited for the optimal algorithm development.

In normal EPGS operation the capacity of the power resources will be adequate to supply the entire electrical loads of the aircraft. However, in the event of some faults in the power system, or if one of the main power sources unavailable, the remaining power capacity may not be sufficient to supply the entire electrical loads. This demands switching of some of the non-essential loads. In the earlier aircraft it was done manually. In the modern aircrafts with state-of-the art avionics systems on board, it is difficult to have a manual control on various electrical loads. A microcomputer/controller based power controller is required for this operation. For the aircraft with multiple engines, the power distribution management consists of two main stages: adaptive system reconstructing and auto electrical loads shedding. The conventional algorithms will not consider the health status and RUL of the power sources or component it is using for reconfiguration. In some load control equation, it is so happened that the load management algorithm will command a power source to cut-in with very few RUL left for operation. This may introduce a secondary failure after reconfiguration if RUL is small. These problem can be avoided by adding a Health Status membership function in the power management equation. A typical probability distribution function for the health status and RUL prediction were carried out in previous section. The Health status function and RUL data will be effectively used for the Power Management Algorithm development.

Firstly, the Bus controller (BPCU) collects the status of flight mission profiles/flight phases, Variable priority level, Variable Power level requirements, PHM status of EPGS system and the status of power sources in real time. When the bus controller detect any failure in EPGS system adaptive reconfiguration algorithm will be executed. The reconfiguration process mainly happens in the primary power controllers. PHM and health status from various LRU with RUL data will be effectively utilized reconfiguration as shown in Figure-20. 
After the adaptive reconfiguration process, the bus controller will look for the electrical load management algorithm. Based on the variable load priority profile and with effective utilization of the overload capacity of generators and operating envelop of slow responding loads, the load management algorithm will be executed.ELMCs will normally execute the load management algorithm based on the Bus controller commands. Then, some non-essential loads will be shed automatically as given in the flowchart in Figure-21.According to the flight phase or mission requirements, electrical power requirement is calculated. Then the load management algorithm will calculate the current control command of each load, and a certain quantity of electrical loads can be supplied with electrical power. The load management function is performed by PPDUs and ELMCs. During flight, PPDUs and ELMCs monitor the status control logic signals, flight phase signals, power channel status, and the current default status of control devices. They then solve the power request equation. Along with the SSPC/Contactor failure status signal, the load shed signal from BPCU, and the override signal from the pilot, the PPDUs and ELMCs will solve the load control equation. Finally, each load will be determined to get power according to the result of the load control equation. The whole process is performed automatically. The BPCU1 knows which generators are in normal operation by monitoring the status of the power sources, and can judge which generator is overloaded and which loads need to be shed to eliminate the overload issues. By using this method, the power capacity of the remaining power sources can be adequately used. This method is much superior to the traditional method (setting load shedding bus bars), which cannot make the best use the available power capacity.

This paper elaborate the importance of the MEA concepts and various power management system development. Various PHM methodology for EPGS system has been described in detail. Various failure mode has been simulated with the injection of faults and disturbances into the system.

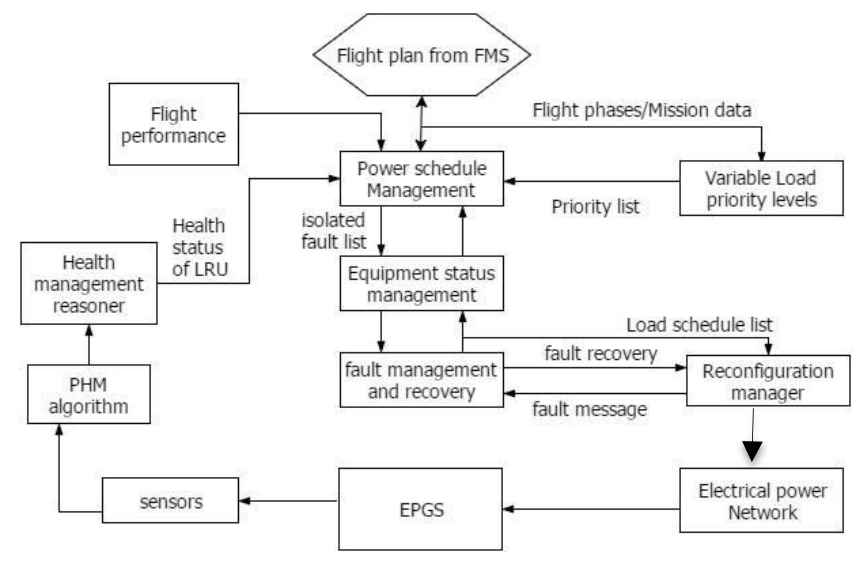

Figure 20. PHM based Power Management Algorithm
PHM reasoner is fused in to the electrical power management system algorithm. The developed fault tolerant algorithm has been implemented on the DSP+FPGA processor to have a fault tolerant power management system design.

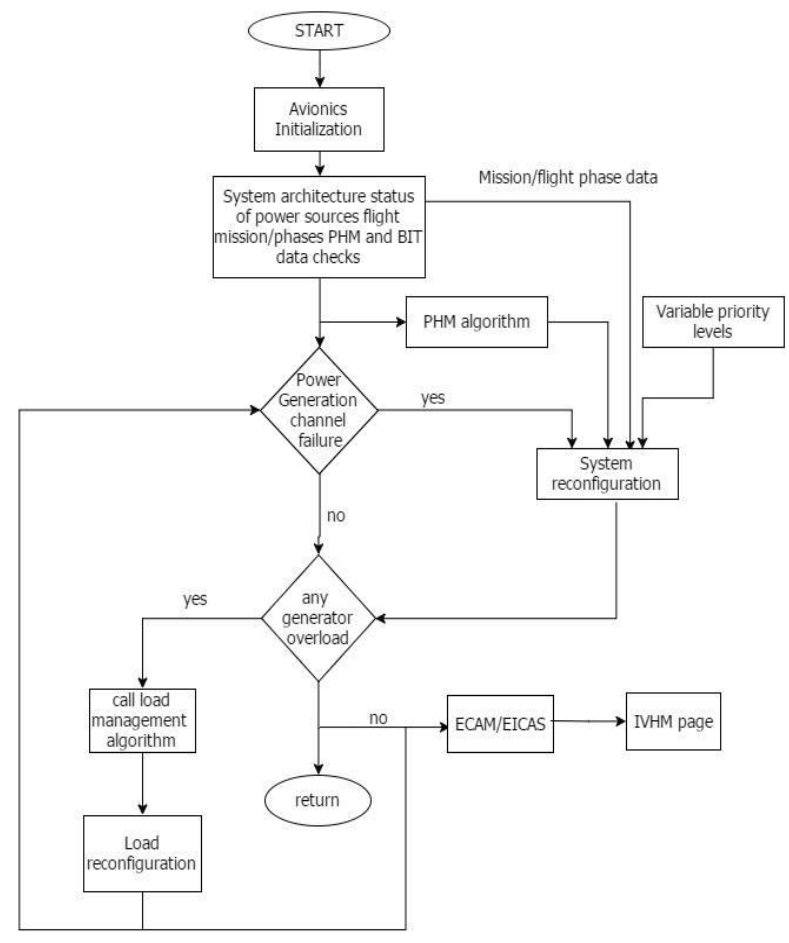

Figure 21. ELMC Algorithm

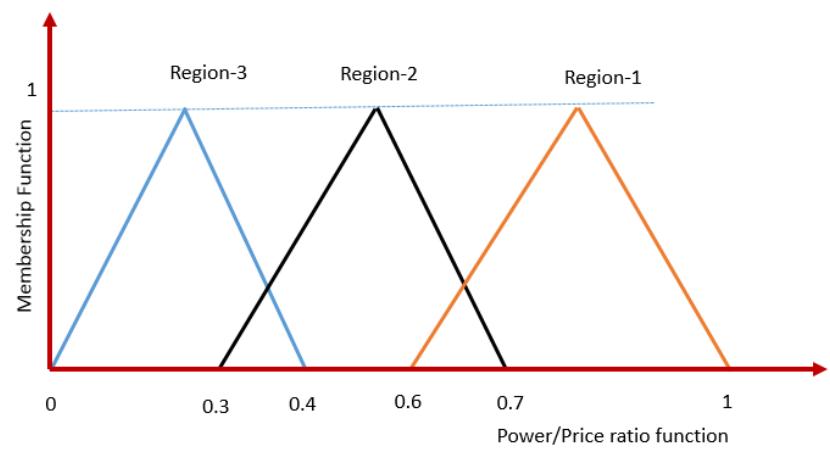

Figure 22. Power Control Function

A typical cost function is defined for both source and load units. The cost function shows the relation between power and price. Based on the cost function for source and load a power request membership function has been generated as shown in Figure-22 which is distributed in three operating regions. In the Region-1 which is having highest power to price ratio, all the connected loads will get its rated power. The generator will supply all the electrical loads at its optimum efficiency. In Region-2 power controlling process at variable power level, switching of loads based on time sharing logic etc. were carried out. The generators will work in its steady state overload capacity. In Region-3 ELMC will 
disconnect all the non-priority loads. An adaptive Fuzzy based power management algorithm were developed. Hardware in loop study was carried out using Kintex-7 FPGA evaluation board for algorithm verification.

\section{Conclusion}

This paper elaborate the importance of the MEA concepts, various power management and load management concepts in aircraft industry.PHM algorithm development of EPGS components were discussed. The conventional modelling of IDG is done with PMG and Exciter Generator assumed to be a constant voltage source. In this research work a mathematical modelling of PMG, Rectifier Bridge modelling of Exciter Generator, d-q modelling of main generators were carried out to make it appropriate for structural fault analysis. A detailed switching harmonics study is carried out to analyse the amount of harmonics fed back to generator circuit and an optimum load switching cycle has been identified. Various parametric and structural failure modes are simulated. Experimental testing of main generator has been carried out to verify the simulation results.

A detailed Electrical Load Analysis has been carried out. A Micro-economical cost function based power management algorithm has been developed. RUL information and health indices from PHM algorithm were fused to power management to make it an adaptive and fault tolerant design.

PHM based Power management design is an important design area in aircraft industry. In the future expansion of algorithm development more EPGS components can be added in PHM and Adaptive algorithm development. The power management system can be developed as an electrical controller which has both PHM and Power System control functionality.

\section{NOMENCLATURE}

Variable Description

$i_{x} \quad$ Winding-x Current, main generator

$\widehat{\iota_{x}} \quad$ Winding-x Current, exciter generator

$v_{x} \quad$ Winding-x Voltage, main generator

$\widehat{v_{x}} \quad$ Winding-x Voltage, exciter generator

$\lambda_{x} \quad$ Winding-x flux linkage, main generator

$\widehat{\lambda_{x}} \quad$ Winding-x flux linkage, exciter generator

$r_{x} \quad$ Winding-x resistance, main generator

$\widehat{r_{x}} \quad$ Winding-x resistance, exciter generator

$\omega \quad$ Electrical angular velocity

$\theta_{r} \quad$ Angular displacement

$T_{m} \quad$ Mechanical Input Torque

$P \quad$ Number of pole pairs of the main/exciter generator

$J \quad$ Rotor Inertia

$D$ Damping coefficient of the mechanical rotational system

$\begin{array}{ll}L_{m q} & \text { Magnetizing inductance, q winding } \\ \dot{L}_{i k q} & \text { Leakage Inductance, } k q \text { winding (referred) } \\ \dot{L}_{i f d} & \text { Leakage Inductance, } f d \text { winding (referred) } \\ \dot{L}_{i k d} & \text { Leakage Inductance, } k d \text { winding (referred) } \\ r_{a} & \text { Resistance, stator winding } a \\ r_{b} & \text { Resistance, stator winding } b \\ r_{c} & \text { Resistance, stator winding } c \\ \dot{r}_{k q} & \text { Resistance, kq winding } \\ \dot{r}_{f d} & \text { Resistance, fd winding } \\ \dot{r}_{k d} & \text { Resistance, kd winding } \\ N_{s} & \text { Number of turns,stator winding } \\ N_{f d} & \text { Number of turns,fd winding } \\ N_{k q} & \text { Number of turns,kq winding } \\ N_{k d} & \text { Number of turns,kd winding } \\ \mathrm{D} & \text { Damping Coefficient } \\ \mathrm{J} & \text { Moment of Inertia } \\ & \\ L_{A} & \text { Machine geometrical Parameter } \\ L_{B} & \text { Machine geometrical Parameter } \\ L_{l k q} & \text { Leakage inductance, kq winding } \\ L_{m k q} & \text { Magnetizing inductance, kq winding } \\ & \end{array}$

\section{APPENDIX}

Mathematical Modelling of IDG:

In the conventional IDG mathematical model, the PMG and Exciter Generators were assumed to be constant voltage source and were replaced by constant voltage values. A better modelled IDG was shown, but it used constant voltage source for PMG modelling. For a better and accurate mathematical modelling a hybrid modelling method was suggested and PMG performance also mathematically analysed. The output of the PMG system is connected to exciter field winding. The Exciter Generator and Rectifier Bridge were effectively modelled. It is used in the simulation modelling. The parameter matrix $\mathrm{M}, \mathrm{N}$ are calculated and results are calculated. $\mathrm{L}$ is the inductance matrix. $\mathrm{R}$ is the resistance matrix. This resistance are functions of 'theta' which is time varying parameter.

$L_{i s} \quad$ Leakage Inductance, stator winding

$L_{m d} \quad$ Magnetizing inductance, $\mathrm{d}$ winding 


$$
\begin{aligned}
& \dot{\lambda}_{a}=r_{a} i_{a}+v_{a} \\
& \dot{\lambda}_{b}=r_{b} i_{b}+v_{b} \\
& \dot{\lambda}_{c}=r_{c} i_{c}+v_{c} \\
& \dot{\lambda}_{k q}=-r_{k q} i_{k q} \\
& \dot{\hat{i}}_{a}-\dot{i}_{f d}=0 \\
& \dot{\lambda}_{k d}=-r_{k d} i_{k d} \\
& \dot{\hat{\lambda}}_{a}-\dot{\hat{\lambda}}_{b}-\dot{\lambda}_{f d}=\left(\hat{r}_{a}+\hat{r}_{b}+r_{f d}\right) \hat{i}_{a} \\
& \dot{\hat{i}}_{a}+\dot{\hat{i}}_{b}=0 \\
& \dot{\hat{i}}_{c}=0 \\
& \dot{\hat{\lambda}}_{f d}=-\hat{r}_{f d} \hat{i}_{f d}+V_{F} \\
& \dot{\omega}=\frac{P}{2 J}\left(T_{m}-T_{e}-\hat{T}_{e}-D \omega\right) \\
& \dot{\theta}_{r}=w . \\
& \lambda=\mathbf{L i} \quad \Rightarrow \quad \dot{\lambda}=\mathbf{L} \dot{\mathbf{i}}+\dot{\mathbf{L}} \mathbf{i} \\
& \text { Where, } \\
& \lambda=\left[\begin{array}{llllll}
\lambda_{a} & \lambda_{b} & \lambda_{c} & \lambda_{k q} & \lambda_{f d} & \lambda_{k d}
\end{array}\right]^{T} \\
& \mathbf{i}=\left[\begin{array}{llllll}
i_{a} & i_{b} & i_{c} & i_{k q} & i_{f d} & i_{k d}
\end{array}\right]^{T} \\
& \hat{\lambda}=\left[\begin{array}{llll}
\hat{\lambda}_{a} & \hat{\lambda}_{b} & \hat{\lambda}_{c} & \hat{\lambda}_{f d}
\end{array}\right]^{T} \\
& \hat{\mathbf{i}}=\left[\begin{array}{llll}
\hat{i}_{a} & \hat{i}_{b} & \hat{i}_{c} & \hat{i}_{f d}
\end{array}\right]^{T} \\
& \mathbf{R}=\left[\begin{array}{lllllll}
r_{a} & r_{b} & r_{c} & -r_{k q} & 0 & -r_{k d} & \hat{r}_{a}
\end{array}\right. \\
& \left.+\hat{r}_{b}+r_{f d} \quad 0 \quad 0 \quad-\hat{r}_{f d}\right] \\
& \mathbf{u}=\left[\begin{array}{llllllllll}
v_{a} & v_{b} & v_{c} & 0 & 0 & 0 & 0 & 0 & 0 & V_{F}
\end{array}\right]^{T} . \\
& {\left[\begin{array}{c}
\mathbf{i} \\
\dot{\hat{\mathbf{i}}}
\end{array}\right]=\mathbf{M}^{-1}(\mathbf{N}+\mathbf{R})\left[\begin{array}{l}
\mathbf{i} \\
\hat{\mathbf{i}}
\end{array}\right]+\mathbf{M}^{-1} \mathbf{u}} \\
& \dot{\omega}=\frac{P}{2 J}\left(T_{m}-T_{e}-\hat{T}_{e}-D \omega\right) \\
& \dot{\theta}_{r}=w .
\end{aligned}
$$

\section{REFERENCES}

Ferrell, B. L. (1999), JSF Prognostics and Health Management. Proceedings of IEEE Aerospace Conference. March 6-13, Big Sky, MO. doi: 10.1109/AERO.1999.793190

Schwabacher, M., \& Goebel, K. F. (2007). A survey of artificial intelligence for prognostics. Proceedings of AAAI Fall Symposium, November 9-11, Arlington, VA. www.aaai.org/Library/Symposia/Fall/2007/fs07-02016.php

Vachtsevanos, G., Lewis, F. L., Roemer, M., Hess, A., \& Wu, B. (2006). Intelligent fault diagnosis and prognosis for engineering system. Hoboken, NJ: John Wiley \& Sons, Inc.

Felder,J.L., Kim,H. DandBrown,G.V(2009), Turboelectric Distributed Propulsion Engine Cycle Analysis for Hybrid-Wing Body Aircraft,AIAA-2009 1132,presented at $47^{\text {th }}$ AIAA Aerospace sciences meeting,5-8 January 2009. Orlando,Florida,USA.

Rosero, J.A, OrtegaJ.a, Aldabas, E.Romeral, L, (2007), Moving towards a more electric aircraft, Aerospace and Electronic Systems Magazine, IEEE, Vol: 22, Issue: 3, Page (s):3-9.

A.Tantawy and G Biswas, (2008), Aircraft AC Generators: Hybrid system Modelling and Simulation, International Conference on Prognostics and Health Management, IEEE.

Todd D. Batzel and D.C. Swanson, Prognostic Health Management of Aircraft Power Generators, Aerospace and Electronics System, IEEE, Vol.45, No: 2, Page(s) 473-482.

Connally, H.M, Lodge, I, Jackson, R.J and Roberts.I, Detection of Interturn faults in generator rotor windings using airgap search coil, (1985),IEEE page(s),11-15.

Sottile,J,Trutt,F.C, and Leedy,A.W. Condition monitoring of brushless 3-phase synchronous generators with stator winding or rotor circuit deterioration,Industry Applications,IEEE,2001,page(s)1587-1594.

Zouaghi, T, and Poloujadoff. M. Modelling of polyphase brushless exciter behaviour for failing diode operation, IEEE Transactions on Energy Conversion, B, 3(Sept.1998), 214-220.

H.Pan, E.Dong,Y.Jiang,P Zhang A Prognostics and Health Management for Aircraft Electrical Power Supply System, IEEE conference on Prognostics \& system health Management PHM-2012.

Aircraft Electrical Power Characteristics, Department of Defence of USA, March 2004.

A.Ginart, I.Barlas, J.L.Dorrity, P.Kalgen and M.J Roemer Self-healing from a PHM perspective, IEEE transactions 2006, page(s) 697-703.

L. Andrade and C. Tenning, Design of the Boeing 777 Electric system, AES Magazine, IEEE, July 1992. 
A.A.AbdElhafez and A.J.Forsyth, A review of more-electric aircraft", in $13^{\text {th }}$ international conference on Aerospace Science and Aviation Technology, ASAT-13, 2009.

D.Schlabe,J.Lienig, Energy Management of aircraft Electrical systems-state of the art and further direction, IEEE proceedings Railway and ship propulsion (ESARS), 2012.

X.Xia, and C.P.Lawson, The development of a design methodology for dynamic power distribution management on a civil transport all electric aircraft, Aerospace Science and Technology 25(2013), 125-131.

Procedures for performing failure Mode Effects and criticality Analysis US MIL-STD-1629A, Nov, 1980.

Fitzgerald, A.E, Kingsley.C, and Umans.S.D, Electrical Machinery, (6 ${ }^{\text {th }}$ ed.)New York McGraw-Hill, 2003.

H.Pan,E.Dong,Y.Jiang,P.Zhang, Prognostic and Health Management for Aircraft Electrical Power Supply system,(2002),IEEE,Prognostics\&System Health Management Conference, Beijing.

D.Schlabe and J.Lieneg Energy Management of Aircraft Electrical System-State of the Art and Further Direction In Proc. Electrical Systems for Aircraft, Railway and Ship Propulsion, 2012.

J. Joupes, S.Nellis D, Hamblays and M.Peabody, Load distribution and Management System, EP Patent 1,143,593,A1,2001.

Chee Mun Ong, Dynamic Simulation of Electric Machinery by MATLAB Simulink, Prentice Hall PTR.

Schlabe.D, and Zimmer.D , Model based Energy Management Function for Aircraft Electrical System, In Proc. SAE, 2012.

\section{BIOGRAPHIES}

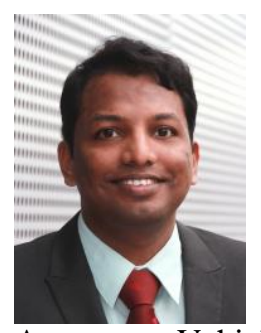

Robin.K.Sebastian is currently working as Deputy Manager (Design) at Hindustan Aeronautics Limited (HAL), Bangalore, India. He had more than 7 year experience in the aircraft design industry with wide range of expertise spread across EPGS design, Flight testing, IVHM and Avionics Integration. $\mathrm{He}$ is doing his MSc in Aerospace Vehicle Design in Avionics System Design at Cranfield University, UK for the year 2015-16. He has done his Bachelor Degree in Electrical \& Electronics Engineering from University of Calicut, India during 2003-07. He also done his Diploma in Electrical Engineering from Gov. Polytechnic College, Trichur, India in 1999-2002.

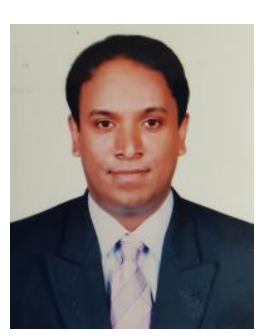

Suresh Perinpanayagam received the M.Eng. and D.Phil. degrees from Imperial College London, London, U.K., in 2004. He is a Lecturer at the Integrated Vehicle Health Management (IVHM) Centre, Cranfield University, Bedford, U.K., where he heads the Electronics Prognostics Group, which works on highly accelerated life testing, electro thermal modelling, thermomechanical modelling, reliability and failure assessment capabilities for renewable energy systems, automotive, aerospace, and rail applications. This laboratory develops data-mining techniques for anomaly detection, diagnostics, prognostics, and predictive maintenance for power electronics from the aforementioned industry sectors.

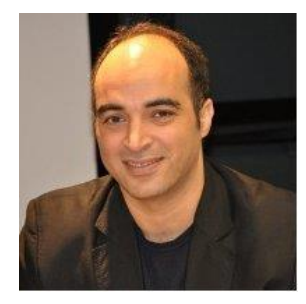

Alireza Alghassi works as a research fellow at IVHM Centre, Cranfield University, UK. He received his B.Sc. degree in Electrical Power Engineering from Iran and Control System Engineering from Sheffield University and M.Sc. in Power Electronic Engineering from Nottingham University. His Ph.D. was in self-aware power electronics from Cranfield University, U.K., in 2016. As a researcher fellow, his duties are to focus on the development of model-based models for real time diagnostic and prognostic along with developing statistical methods for hypothesis testing in power electronics system, the selfawareness power electronic project is benefited for more electric aircraft and EV sectors pursuing partners (Boeing), and renewable energy (Solar farms) where the availability of the vehicles are a key factor in the maintenance policies. 